\title{
Does A Long-Run Relationship Exist between Agriculture and Economic Growth in Thailand?
}

\author{
Chalermpon Jatuporn (Corresponding author) \\ Department of Applied Economics, National Chung Hsing University \\ 250, Kuo-Kuang Rd., Taichung 402, Taiwan, ROC
}

Tel: 886-9-3627-7169 E-mail: jatuporn_c@yahoo.com; jatuporn.ku61@gmail.com

Li-Hsien Chien

Department of Applied Economics, National Chung Hsing University

250, Kuo-Kuang Rd., Taichung 402, Taiwan, ROC

E-mail: 1hchien@nchu.edu.tw; hankchien72@hotmail.com

Patana Sukprasert

Department of Agricultural Extension and Communication, Kasetsart University

50 Phahon-Yothin Rd., Bangkok 10900, Thailand

E-mail: agrpasu@ku.ac.th; patanapom@hotmail.com

Supaporn Thaipakdee

Department of Agricultural Extension and Communication, Kasetsart University

Kamphaeng Sean Campus, Nakhon Pathom 73140, Thailand

E-mail: agrspp@ku.ac.th

Received: July 20, $2010 \quad$ Accepted: January 13, $2011 \quad$ doi:10.5539/ijef.v3n3p227

\begin{abstract}
This empirical study investigates the causality between agriculture and economic growth in Thailand over the period of 1961 to 2009. A Granger causality approach and the Wald $\left(\chi^{2}\right)$ coefficient statistic are utilized to reveal a long-run causal relationship and impact transmission between the variables. Based on the time series analyses, a long-run relationship and size impact are detected running from agriculture to economic growth, and vice versa. These findings including with the generalized variance decomposition show that agriculture is existed in a long-term stable in economic growth while economic development encourages the growth of agriculture as a whole. As a conclusion, policy-makers should regard agriculture as an important supporter of Thai economy.
\end{abstract}

Keywords: Agriculture, Economic growth, Thailand, Toda and Yamamoto, Causality

JEL Classification: C22, C32, C53, O11, O53, Q10

\section{Introduction}

In developing country, agriculture is steadily important and considered as a leading strategy of economic growth. Thailand in particular, has been regarded as agricultural country with the recognition of agriculture-oriented in economy since the booming of green revolution after the first of the National Thai Socio-Economic Development Plan in the 1960s. Almost 50 years, their policies have focused on the development aspect in agriculture because it plays as the image of an important sector in the growth of whole economy as well as domestic labor in terms of its contribution to employment generation. In other words, agriculture is like a primer engine to support the part of sub-economies whereby raw material input and workforce transformations.

Thailand is the medium country belonging in the Southeast Asia, which is 513,115 square kilometers for the country size, and which 41 percent or 21,196,571 hectares is performed as an agricultural area (Ministry of Agriculture and Cooperatives, 2005). Thailand is the top of the world leader in producing and exporting of agricultural productions such as rice, natural rubber, cassava, pineapple, fresh fruits, vegetables, cereals, sugar cane, orchids, black tiger prawns, chicken meat and fishery products (FAO, 2009: Ministry of Foreign Affairs, 2010). Because of this, Thailand was ranked fifth worldwide of the agricultural and food producing countries and 16th of the world's agriculture and 
food produce exporting countries in the last of the 2000s (Ministry of Foreign Affairs, 2010).

Statistical records in the end of 2009 present that agricultural sector generated a total revenue of 1,049,266 million baht, accounting for $11.60 \%$ of the overall gross domestic products (GDP), and reflecting an increase of $240.73 \%$ over the previous ten years or approximately $5,000 \%$ for the past fifty years, which are shown the trend in growth of agriculture and whole economy by Figure 1 (Office of the National Economic and Social Development Board (ONESDB), 2010). Therefore, agriculture is the economic engine that pushes the growth up over the past of 50 years in Thailand. Although the agriculture has significantly an important sector for Thai's economies as we mentioned earlier, but agricultural researchers have not paid much attention to the empirical assessment of contributions whether agriculture is led increasing in growth by economic development, or/and agriculture can lead to increase of economic growth as well.

This study examines the causal effect relationship between agriculture and economic growth in Thailand by focusing on the Granger causality through Toda and Yamamoto (1995) approach. The remainders of this study are organized as follow: Next section presents the literature review and, then the data used and econometrics methodology are provided in Section 3, consisting of a unit root test for stationary of data time series, a Granger causality test for long-run causal relationship, a Wald $\left(\chi^{2}\right)$ coefficient statistic for impact transmission between agriculture and economic growth variables, and a generalized variance decomposition for the relative shock of exogenous and endogenous by forecasting for ten years forward. Afterwards, the empirical results are revealed in Section 4 for the econometrics testing. The conclusions and policy implications are stated in the final section.

\section{Literature review}

Arguments concerning the role of agriculture as the main determinants of economic growth are generally provided by trade aspect. Theoretical augments have supported the relationship between agriculture and economic growth that related to trade (exports and imports) as the study of Thornton $(1996,1997)$ that found export-led economic growth in Italy, Norway, Sweden and Mexico by employing the Granger causality in terms of a vector error correction model (VECM). Likewise, Love and Chandra (2005) studied between trade and economic growth by using three time series analysis techniques, namely, unit root, co-integration and causality. The results revealed that India, Maldives and Nepal were export-led economic growth as well as they found the growth-led exports in the cases of Bangladesh and Bhutan. In Thailand was also supported the hypothesis of export-led economic growth by the study of Thungsuwan and Thompson (2003) and Vohra (2006) that presented a positive impact in short-term and long-term relationships of exports and economic growth.

However, historical experiences have revealed that the developing countries, in particular Asian communities have derived their economic growth by the improvement of agriculture, starting with the study of Katircioglu (2006) that investigated the relationship between economic growth and agriculture in North Cyprus over the period of 1975 to 2002. The time series analysis was performed by using a vector autoregressive (VAR) system. The results indicated a long-run relationship running from economic growth to agriculture, and vice versa. To confirm the study of Katircioglu (2006), Katircioglu (2004-2005) examined the relationship between economic growth and agriculture including industry and service sectors over the period of 1977 to 2002 . The findings were shown that agriculture in North Cyprus has stilled important for economic development in long-term, including with the other variables as well as economic growth can improve the development of agriculture. Tiffin and Irz (2006) also agreed that agriculture can lead in growth of gross domestic products, developing countries in particular, by using panel time series through unit root, co-integration, and Granger causality approaches from 85 counties. In addition, Konya and Singh (2009) studied the causal relationship between international trade and domestic product focused on Indian agricultural and manufacturing sectors, starting from the beginning of 1950 to the end of 2003. The research consisted of unit root, co-integration and Granger causality based on the vector error correction model (VECM). As the conclusion, this study confirmed that agriculture can support in economic growth of India's case.

The focus in this study is on the causal relationship between agriculture and economic growth in Thailand by employing the Granger causality through Toda and Yamamoto (1995) which a long-run causal relationship can be identified without requiring the pre-testing of co-integration as the above literatures. While the following hypotheses are considered in order to verify a long-term stable in the case of Thailand.

Hypothesis 1: Agriculture leads to an increase of the economic growth in forms of the long-term stable for the case of Thailand (Hypothesis: uni-directional relationship; agriculture-led economic growth).

Hypothesis 2: Economic growth leads to an increase in the growth of agriculture in forms of the long-term stable for the case of Thailand (Hypothesis: uni-directional relationship; economic growth-led growth in agriculture).

Hypothesis 3: An increase in the growth of agriculture and economic growth are a causal effect in each other in forms of the long-term stable for the case of Thailand (Hypothesis: bi-directional relationship between the two variables). 


\section{Econometric methodology}

Annual data are obtained from the Office of the National Economic and Social Development Board of Thailand (ONESDB) starting from 1961 to 2009 throughout the period of the National Thai Socio-Economic Development Plan. The variables are presented by 1) the value of gross domestic product of agriculture (AGRI) which utilizes as the proxy for agriculture variable, and 2) the total value of gross domestic products (GDP) which utilizes as the proxy for economic growth variable. Both of two time series are in terms of the current market price, and the trend of growth for agriculture and whole economy are plotted in the Figure 1.

The time series analysis is employed in this article which can be separated into five steps. First is unit root, when the time series are estimated the relationship as an autoregressive (AR) system using ordinary least squares (OLS), the benefit of its outcomes will be invalid of higher $\left(\mathrm{R}^{2}\right)$ and $t$-statistic values, if the stochastic is relied to be the process of non-stationary with no economic denotation (Granger and Newbold, 1974). The non-stationary means that the mean and variance of the time series are unstable throughout the period of the time and the auto-covariance is varying by the time change (Enders, 2004). As these concerning, the Augmented Dickey-Fuller (ADF) is utilized to indicate the properties of time series (Dickey and Fuller, 1979, 1981) by using the models in Eqs. (1-3) as follow:

Firstly, the general unit root model is considered without constant and time trend effect.

$\Delta \mathrm{Y}_{t}=\beta_{1} \mathrm{Y}_{t-1}+\sum_{i=1}^{p} \beta_{2 i} \Delta \mathrm{Y}_{t-i}+\varepsilon_{t}$

Secondly, the general unit root model is included with constant only.

$\Delta \mathrm{Y}_{t}=\alpha+\beta_{1} \mathrm{Y}_{t-1}+\sum_{i=1}^{p} \beta_{2 i} \Delta \mathrm{Y}_{t-i}+\varepsilon_{t}$

Thirdly, the general unit root model is completed with constant and time trend effect.

$\Delta \mathrm{Y}_{t}=\alpha+\delta T+\beta_{1} \mathrm{Y}_{t-1}+\sum_{i=1}^{p} \beta_{2 i} \Delta \mathrm{Y}_{t-i}+\varepsilon_{t}$

where $\Delta$ is the different order, $\mathrm{Y}_{t}$ is the observation (time series), $\alpha$ is the constant term, $T$ is the time trend effect, $p$ is the optimal lag value which is selected based on the lowest value of Schwartz information criterion (SIC), and $\varepsilon_{t}$ is the error term.

The second step is the Granger causally through Toda and Yamamoto (1995) approach by applying a vector autoregressive (VAR) model with lag $\left(k+d_{\max }\right)$. As the alternative Granger causality test, when the process is considered for a long-run causal relationship, and that the time series should contain unit root, stationary at the same order of its integration, and then co-integrated (Engle and Granger, 1987; Granger 1988). However, the procedure by Toda and Yamamoto (1995) has been found superior accuracy in any potential of non-stationary and co-integration between the time series before testing for the causality. Therefore, this procedure is utilized to present the direction of a long-run causal relationship between agriculture and economic growth which can be expressed by following a bi-variate regressive model:

$\operatorname{AGRI}_{t}=\alpha_{1}+\sum_{i=1}^{k} \psi_{1 i} \mathrm{AGRI}_{t-i}+\sum_{i=1}^{d \cdot \max } \psi_{2 i} \mathrm{AGRI}_{t-i}+\sum_{i=1}^{k} \psi_{3 i} \mathrm{GDP}_{t-i}+\sum_{i=1}^{d \cdot \max } \psi_{4 i} \mathrm{GDP}_{t-i}+u_{1 t}$
$\mathrm{GDP}_{t}=\alpha_{2}+\sum_{i=1}^{k} \xi_{1 i} \mathrm{GDP}_{t-i}+\sum_{i=1}^{d \cdot \max } \xi_{2 i} \mathrm{GDP}_{t-i}+\sum_{i=1}^{k} \xi_{3 i} \mathrm{AGRI}_{t-i}+\sum_{i=1}^{d \cdot \max } \xi_{4 i} \mathrm{AGRI}_{t-i}+u_{2 t}$

where $d_{\max }$ is the maximum of lag order of integration, $k$ is the VAR lag selection which is based on the sequential modified $\log$ likelihood (LR) and the final prediction error (FPE) statistics, and $u_{\mathrm{t}}$ is the white noise. The null hypothesis of $\psi_{3 i}$ and $\xi_{3 i}$ equals to zero.

However, Eqs. (4) and (5) employ the Wald $\left(\chi^{2}\right)$ statistic that is performed on the $k$ parameters. The VAR with lag $(k$ $\left.+d_{\max }\right)$ system is conducted whereby an asymptotic Chi-square distribution with $k$ degrees of freedom $\left(\chi^{2}(k)\right)$. The explanation of Granger causality as Toda and Yamamoto (1995) can say that if a time series GDP is a causal for time series AGRI, and if the past of GDP $\left(\mathrm{GDP}_{t-1}, \mathrm{GDP}_{t-2}, \mathrm{GDP}_{t-3} \ldots, \mathrm{GDP}_{t-k}\right)$ can support to predict of AGRI (AGRI) with greater accuracy. In other words, GDP is a causal effect of AGRI in a long-term stable, whereas, if a time series AGRI is a causal for time series GDP, and if the past of AGRI (AGRI ${ }_{t-1}$, AGRI $_{t-2}$, AGRI $_{t-3} \ldots$, AGRI $_{t-k}$ ) can support to predict of GDP $\left(\mathrm{GDP}_{t}\right)$ with greater accuracy. In other words, AGRI is also a causal effect of GDP in a long-term stable.

As the result, the Granger causality can identify an existence of a long-run relationship. Next step, the Wald $\left(\chi^{2}\right)$ 
coefficient statistic is employed to reveal the size impact of its relationship as the study of Johansen and Juselius (1994) and Apergis and Rezitis (2003) which estimated the impact transmission of the causal relationship between the variables. Furthermore, the result from this technique can measure the size of impact between agriculture and economic growth when the rate of change rises(falls) by one percent in agriculture or/and economic growth.

To reach beyond the above tests that limit in the sample period, the last step is the forecast of error variance decomposition for ten years forward prediction by using the technique of Pesaran and Shin (1998). The generalized variance decomposition can measure the relative shock proportions of exogenous and endogenous whereby $n$-step forecasting ahead of error variance $(\varepsilon)$. The generalized forecast error variance decomposition $(\Theta)$ can be expressed as follows:

$$
\Theta_{i j}(n)=\frac{\sigma_{i i}^{-1} \sum_{l=0}^{n}\left(e_{i}^{\prime} M_{l} \sum e_{j}\right)^{2}}{\sum_{l=0}^{n} e_{i}^{\prime} M_{l} \sum M_{l}^{\prime} e_{i}}, i, j=1, \ldots, m .
$$

where $M$ is the $m \times m$ coefficient metrics, $n=0,1,2, \ldots, 10$, and $e_{j}$ is the white noise.

In this study, the generalized variance decomposition is utilized to predict the risk of shock by using the error variance from Eqs. (4)-(5) systems. The approach points out to the proportion of the error variance which can be explained by the changes in another variable. And, also the findings can be identifying the future shock in agriculture and economic growth systems that how each variable responses to the shocks in the other variable.

\section{Empirical results}

The study is accomplished by using four time series analyses, namely, unit root, Granger causality, Wald $\left(\chi^{2}\right)$ coefficient statistic, and generalized variance decomposition tests. The results from the diagnoses can answer three concerned questions: 1) what is the causal effect relationship between agriculture and economic growth variables in Thailand, 2) if (1) exists, what is the size impact of its transmitted relationship, and 3) how the shock effects to the future momentum in the ten years forwards. Before performing, it should be indicated the properties of time series. The unit root is widely used presenting for stationary of time series which this study utilizes whereby the ADF unit root.

The results of unit root are listed in Table 1, the ADF unit root tests has been conducted by the most general model with a constant and time trend effect $\operatorname{ADF}\left(\tau_{T+\alpha}\right)$, with a constant and without time trend effect $\operatorname{ADF}\left(\tau_{T}\right)$, and without a constant and time trend effect $\operatorname{ADF}(\tau)$. The null hypothesis of the unit root is non-stationary in each individual time series. The results of the ADF unit root tests in Table 1 show that the time series are found non-stationary in level and at the first difference, except AGRI series that appears to be stationary at the first difference when the model includes a constant and time trend effect in testing. After performing the second difference, all of the variables are found to be stationary. Therefore, the results of the unit root in Table 1 indicate that the integration orders of all variables do not appear to be exceeding order 2 , which can be identified $d_{\max }$ as an order 2 . It can be concluded that $d_{\max }$ is an order 2 .

In addition, based on the VAR lag order $(k)$ selection criteria of sequential modified log likelihood (LR) and the final prediction error (FPE) test statistics, the lag order of 14 is the lowest value of the optimal lag selection.

After we perform the Granger causality by applying the VAR model with lag $(14+2)$, the results in Table 2 show that a long-run causal effect is detected in bi-directional relationship running from agriculture (AGRI) to economic growth (GDP), and vice versa with statistical significance at $5 \%$ level. The findings reveal that agriculture is a causal effect to economic growth and also economic growth is a causal effect to agriculture, both in long-run relationship. Therefore, increasing in the growth of both agriculture and economic growth are a causal effect in the long-term stable of each other for the case of Thailand, which confirms for the hypothesis of (3).

Once a bi-direction of the long-run causal relationship has been found in Table 2, then the Wald $\left(\chi^{2}\right)$ coefficient statistic is employed to measure for a size impact that transmits between these two variables.

The results of the Wald $\left(\chi^{2}\right)$ coefficient statistic in Table 3 are presented the impact transmission between agriculture and economic growth variables. The findings show that if the rate of change in agriculture rises(falls) by 1 percent then the rate of change in economic growth will increase(decrease) by 0.142 percent, whereas, if the rate of change in economic growth rises(falls) by 1 percent then the rate of change in agriculture will increase(decrease) by 1.535 percent. The results of the estimated size impact are shown a positive transmitted relationship in two-way directional relationship between agriculture and economic growth variables.

As the findings of Table 4, the generalized variance decomposition results are consistent with the Wald $\left(\chi^{2}\right)$ coefficient statistic tests that economic growth is a main significant effect on agriculture when the tenth year is forecasted reflecting $94 \%$ of the shock proportion in agriculture system. This result also presents that agriculture can sustain on significant of its own shock when eighth year is forecasted and then economic growth becomes a large 
significant shock proportion starting from the ninth year. Turning to economic system, economic growth is a large effect shock reflecting over $90 \%$ of the shock proportion in its own system for the time forecasting, except the third year that is approximately $87 \%$ of the shock proportion.

\section{Conclusions and policy implications}

Agriculture has been regarded as a key sector in economic growth in Thailand throughout its history. This study employs the time series techniques to analyze the causal relationship and size impact transmission between agriculture and economic growth in Thailand over the period of 1961 to 2009. A bi-variate vector autoregressive (VAR) system including the tests of four diagnoses, namely, the unit root, the Granger causality, the Wald $\left(\chi^{2}\right)$ coefficient statistic, and the generalized variance decomposition is utilized to answer the purpose of our questions. As the results, a long-term stable is detected in bi-directional relationship running from agriculture to economic growth and from economic growth to agriculture. Also, economic growth is a key factor for increasing in growth of agriculture significantly. In the conclusion, this empirical study reveals that agriculture in Thailand seems to be a successful sector in terms of their macro-policy and its implication throughout the period of the National Thai Socio-Economic Development Plan. In particular, therefore, policy-makers should pay more attention to the micro-scale unit for Thai farmers and also overseas agribusiness in forms of the benefit equivalence to agricultural societies.

\section{References}

Apergis, N., \& Rezitis, A. (2003). Mean spillover effects in agricultural prices: The case of Greece. Agribusiness, 19(4), 425-437.

Dickey, D., \& Fuller, W. A. (1979). Distributions of the estimators for autoregressive time series with a unit root. Journal of the American Statistical Association, 74(366), 427-431.

Dickey, D., \& Fuller, W. A. (1981). Likelihood ratio statistics for autoregressive time series with a unit root. Econometrica, 49(4), 1057-1072.

Enders, W. (2004). Applied econometric time series. (2nd ed.). New York: John Wiley \& Sons Inc.

Engle, R. F., \& Granger, C. W. J. (1987). Co-integration and error correction: Representation, estimation and testing. Econometrica, 55(2), 251-276.

FAO (2009). Agricultural and food commodities production. Food and Agriculture Organization of the United Nations. [Online] Available: http://faostat.fao.org/site/339/default.aspx (February 3, 2010).

Granger, C. W. J. (1988). Some recent developments in a concept of causality. Journal of Econometrics, 39(1-2), 199-211.

Granger, C. W. J., \& Newbold, P. (1974). Spurious regressions in econometrics. Journal of Econometrics, 2(2), 111-120.

Johansen, S., \& Juselius, K. (1994). Identification of the long-run and the short-run structure: An application to the IS-LM model. Journal of Econometrics, 63(1), 7-36.

Love, J., \& Chandra, R. (2005). Testing export-led growth in South Asia. Journal of Economic Studies, 33(2), 132-145.

MacKinnon, J. G. (1996). Numerical distribution functions for unit root and co-integration tests. Journal of Applied Econometrics, 11(6), 601-618.

Ministry of Agriculture and Cooperatives (2005). Agriculture. Ministry of Agriculture and Cooperatives of Thailand. [Online] Available: http://www.moac.go.th/builder/moac/articleupdate_eng. php?id=28 (November 5, 2010).

Ministry of Foreign Affairs (2010). Thailand in the 2000's: Agriculture. Ministry of Foreign Affairs of Thailand. [Online] Available: http://www.mfa.go.th/multimedia/E_Book/b5.pdf (February 8, 2010).

Katircioglu, S. T. (2004-2005). Co-integration and Causality between GDP, agriculture, industry and service growth in North Cyprus: Evidence from time series data, 1977-2002. Review of Social, Economic and Business Studies, 5/6(Fall), 173-187.

Katircioglu, S. T. (2006). Causality between agriculture and economic growth in a small nation under political isolation: A case from North Cyprus. International Journal of Social Economics, 33(4), 331-343.

Kmenta, J. (1986). Elements of econometrics. New York: MacMillan Publishing Co.

Konya, L., \& Singh, J. P. (2009). Causality between international trade and gross domestic product: The case of the Indian agricultural and manufacturing sectors. International Journal of Economics and Business Research, 1(1), $61-75$.

ONESDB (2010). Quarterly gross domestic product. The Office of the National Economic and Social Development 
Board of Thailand. [Online] Available: http://www.nesdb.go.th/Default.aspx?tabid=95 (March 3, 2010).

Pesaran, M. H., \& Shin, Y. (1998). Generalized impulse response analysis in linear multivariate models. Economics Letters, 58(1), 17-29.

Tiffin, R., \& Irz, X. (2006). Is agriculture the engine of growth? Agricultural Economics, 35(1), 79-89.

Toda, H. Y., \& Yamamoto, T. (1995). Statistical inference in vector autoregressions with possibly integrated process. Journal of Econometrics, 66(1-2), 225-250.

Thornton, J. (1996). Co-integration, causality and export-led growth in Mexico, 1895-1992. Economics Letters, 50(3), 413-416.

Thornton, J. (1997). Export and economic growth: Evidence from 19th Century Europe. Economics Letters, 55(2), 235-240.

Thungsuwan, S., \& Thompson, H. (2003). Exports and economic growth in Thailand: An empirical analysis. $B U$ Academic Review, 2(1), 10-13.

Vohra, R. (2006). Export and economic growth: Further time series evidence from less-developed countries. International Advances in Economic Research, 7(3), 345-350.

Table 1. ADF unit root tests

\begin{tabular}{|c|c|c|c|c|c|c|}
\hline \multirow{2}{*}{ Variable } & \multicolumn{2}{|c|}{$\operatorname{ADF}\left(\tau_{T+\alpha}\right)$} & \multicolumn{2}{|c|}{$\operatorname{ADF}\left(\tau_{\alpha}\right)$} & \multicolumn{2}{|c|}{$\operatorname{ADF}(\tau)$} \\
\hline & $t$-test & $p$ & $t$-test & $p$ & $t$-test & $P$ \\
\hline \multicolumn{7}{|l|}{ Level } \\
\hline AGRI & 1.240 & 0 & 4.429 & 0 & 6.774 & 0 \\
\hline GDP & -1.379 & 10 & -0.550 & 10 & -1.109 & 10 \\
\hline \multicolumn{7}{|c|}{ First difference } \\
\hline$\Delta \mathrm{AGRI}$ & $-6.226^{*}$ & 0 & -2.262 & 1 & -1.505 & 1 \\
\hline$\Delta \mathrm{GDP}$ & -1.668 & 9 & -0.295 & 9 & 1.440 & 9 \\
\hline \multicolumn{7}{|c|}{ Second difference } \\
\hline$\Delta^{2}$ AGRI & $-12.191^{*}$ & 0 & $-12.379 *$ & 0 & $-12.503 *$ & 0 \\
\hline$\Delta^{2} \mathrm{GDP}$ & $-6.818^{*}$ & 8 & $-7.249 *$ & 8 & $-6.486^{*}$ & 8 \\
\hline
\end{tabular}

$\Delta$ and $*$ denote the different order and statistical significance at $5 \%$ level.

Note: The rejection of ADF null hypothesis bases on MacKinnon (1996) critical values. The optimal lags $(p)$ are selected with the lowest value of Schwartz information criterion (SIC).

Table 2. Long-run Granger causality test

\begin{tabular}{lll}
\hline Independent variable & Dependent variable $(\mathrm{Y})$ & \\
\cline { 2 - 3 }$(\mathrm{X})$ & AGRI & GDP \\
\hline AGRI & - & $158.643^{*}$ \\
GDP & $52.853^{*}$ & - \\
\hline
\end{tabular}

* denotes the statistical significance at $5 \%$ level.

Note: Null hypothesis: X does not Granger cause Y.

Table 3. Impact transmission

\begin{tabular}{lcr}
\hline Causal relationship & $\begin{array}{l}\text { Impact } \\
\text { (standard error) }\end{array}$ & $\begin{array}{l}\text { Wald statistics } \\
(p \text {-value) }\end{array}$ \\
\hline Agriculture to economic growth & 0.142 & $\chi^{2}(1)=12.557$ \\
Economic growth to agriculture & $(0.040)$ & $\begin{array}{r}(0.000) \\
\chi^{2}(1)=12.557 \\
(0.000)\end{array}$ \\
\hline
\end{tabular}

The Wald $\left(\chi^{2}\right)$ coefficient tests the null hypothesis that the impact equals to zero (Kmenta, 1986).

Note: The size impact based on the existences of a bi-direction of the long-run causal relationship from Table 2. 
Table 4. Forecast of generalized variance decomposition

\begin{tabular}{llllll}
\hline \multirow{2}{*}{$\begin{array}{l}\text { Horizon } \\
\text { Year }\end{array}$} & \multicolumn{2}{c}{ AGRI system } & & \multicolumn{2}{c}{ GDP system } \\
\cline { 2 - 3 } \cline { 5 - 5 } 2010 & Shock $_{\text {AGRI }}$ & Shock $_{\text {GDP }}$ & & Shock $_{\text {AGRI }}$ & Shock $_{\text {GDP }}$ \\
2011 & 100.000 & 0.000 & 0.119 & 99.880 \\
2012 & 100.000 & 0.000 & 0.119 & 99.880 \\
2013 & 88.496 & 11.503 & 12.913 & 87.086 \\
2014 & 89.687 & 10.312 & 5.869 & 94.130 \\
2015 & 85.137 & 14.862 & & 5.882 & 94.117 \\
2016 & 81.552 & 18.447 & & 4.843 & 95.156 \\
2017 & 78.425 & 21.574 & & 5.207 & 94.792 \\
2018 & 63.411 & 36.588 & & 4.487 & 95.512 \\
2019 & 22.198 & 77.801 & & 4.811 & 95.188 \\
\hline
\end{tabular}
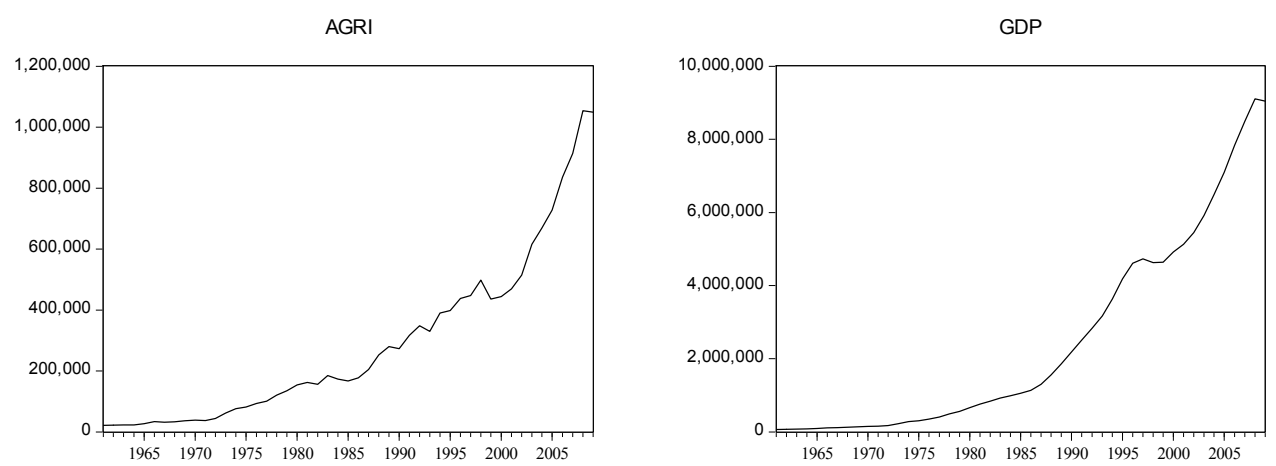

Figure 1. The time trend of AGRI and GDP covering 1961-2009 